\title{
Quantitative characteristics of calcitonin-producing cells in the thyroid and lungs of uremic rats
}

\author{
Irena Kasacka
}

Department of Histology and Embryology, Medical University of Bialystok, Poland

\begin{abstract}
Uremia leads to a number of metabolic and hormonal disorders induced by renal failure with definite biological and clinical sequels. For this reason and the absence of reports on influence of CRF on calcitonin (CT)-producing cells of the thyroid glands and airways, the author decided to investigate the behavior of neuroendocrine cells in experimental uremia, taking CT-producing cells as an example. The aim of the present study was to examine the number and distribution of CT-producing cells in the thyroid glands and lungs of uremic rats. Fragments of the thyroids and lungs were collected one week after nephrectomy. Paraffin-embedded sections were stained with $\mathrm{H}+\mathrm{E}$ and by silver impregnation. To identify neuroendocrine cells, immunohistochemical reaction was performed with the use of a specific antibody against calcitonin. It was revealed that the number of CT-immunoreactive cells decrease in the thyroid and considerable increase in the lungs of rats, when compared to the value in the control animals. The results can be regarded as the morphological manifestation of calcitonin-producing endocrine cells in the rat thyroid and lungs to disorders in the internal environment of the body induced by the impairment of renal parenchyma functioning.
\end{abstract}

Key words: C-producing cells, thyroid, lung, chronic renal failure, rat

\section{Introduction}

Apart from endocrine cells, which accumulate to form either distinct glands such as thyroid or isolated groups of cells within specialized organs, there is an extensive system of neuroendocrine cells that are present among other epithelial cells, especially in the airways [1-3]. A considerable progress has been observed recently in the knowledge on hormones produced by so-called diffuse neuroendocrine system (DNES) or the third nervous system, functioning autonomically and regulating the function of all internal organs [4-6].

Thyroid C cells and pulmonary neuroendocrine (PNE) cells are considered to be part of the DNES, whose cells have a wide range of similar morphological or functional traits. For instance, it was found that some hormones secreted by thyroid $\mathrm{C}$ cells are also produced in PNE cells of the airways [7,8]. Some of the PNE cells contain calcitonin (CT) in their secretory cytoplasmic granules, which is mainly considered as a thyroid $\mathrm{C}$ cell marker hormone. It is generally accepted that most of the CT in the peripheral blood

Correspondence: I. Kasacka, Dept. of Histology and Embryology, Medical University of Bialystok, Kilińskiego $1 \mathrm{Str}$, 15-089 Białystok, Poland; tel./fax.: (+4885) 7485455, e-mail:kasacka@umwb.edu.pl originates from the C cells of the thyroid gland [9]. The capability of PNE cells to secrete CT is an issue that until now has been unresolved.

It is likely that in most airways NE cells the CTgene expression aims mostly at creation of CGRP [10]. Moreover, it is known from other, very few reports that in humans, after a complete thyroid removal, a certain amount of CT is still found in blood, which indicates it is also created by cells in organs other than thyroid itself [11]. Harbarth et al. [12] showed that after total thyroidectomy there is an elevated procalcitonin concentration in blood. Also, NE cells occurring in other organs demonstrate CT gene expression [13] and may also be an additional source of CT occurring in blood after thyroidectomy.

The above considerations based on literature survey [14-18] and our own results [3,19] allow the statement that CRF leads to severe disorders in the system of endocrine cells of the thyroid glands and lungs. These disorders may involve quantitative changes and function impairment, that is disturbances in the mechanisms of the release of polypeptide hormones (dys-

Abbreviations: CRF - chronic renal failure; CT - calcitonin; DNES - diffuse neuroendocrine system; PNEC - pulmonary neuroendocrine cells; NE - neuroendocrine cells; NEB neuroepithelial bodies. 
function, excessive accumulation of polypeptide in secretory granules). However, as long as the mechanisms of mutual relations and interactions are not elucidated, it is difficult to determine whether the clinical symptoms from the thyroid [20,21] and respiratory system $[18,22]$ result from the impairment of structure and function of DNES cells, or are due to the reaction of NE cells to homeostatic disorders. The analyses of literature data and our own results allow the assumption that the clinical symptoms are secondary and result from impaired regulation of DNES cells which produce biogenic amines and peptide hormones involved in the adaptive processes of the organism. More detailed knowledge of the structure and function of neuroendocrine cells will undoubtedly contribute to better understanding of the pathological processes with CT-producing cells involvement and may have a great practical significance in diagnostics; however, the issue still requires a number of investigations.

In order to increase the knowledge on the pathogenesis of thyroid glands and respiratory disorders in $\mathrm{CRF}$, as well as with regards to the lack of reports on the actual behavior of neuroendocrine cells, it seemed fairly interesting to investigated the behavior of neuroendocrine cells in experimental uremia, taking CTproducing cells as an example. The studies aimed at the immunohistochemical localisation and a quantitative evaluation of CT-producing cells in the thyroid and lungs of rats with experimental uremia.

\section{Materials and methods}

Experimental model. The study was performed on 15 young male Wistar rats, their body weight at the beginning of the experiment within 200-220 g (the mean body weight: $210 \pm 10 \mathrm{~g}$ ). The animals were kept in lighted and ventilated conditions with room temperature and maintained day and night rhythm. The animals had a free access to standard granulated chow and drinking water was available. All the experiments were performed at the same time of the day.

Procedures involving the animals and their care were conducted in conformity with the institutional guidelines that were in compliance with national and international law and with guidelines for the use of animals in biomedical research [23].

The experimental rats were divided into two control groups: C - five rats did not undergo any surgical procedure, $\mathrm{SH}$ - five animals underwent a sham operation and one experimental uremic group $\mathrm{U}$ - five rats with experimentally induced uremia according to the method described by Ormord and Miller [24]: surgical resection of one kidney and removal of $70 \%$ of the other kidney cortex.

Method of experimental material collection and fixation. After one week from the surgery, the rats were anesthetized by pentobarbital, administered interperitoneally (i.p.) at a dose of $50 \mathrm{mg} / \mathrm{kg}$ and blood was collected from their hearts. Then, the animals were killed by cutting of heard.

Following thyroidectomy and thoracotomy, thyroid glands and lungs were dissected. Immediately after the preparation of the lungs Bouin's fluid was administered by syringe into the trachea to smooth the pulmonary pleura in the right lung. Following the trachea ligation, the lung and thyroid were fixed in Bouin's fluid for
$24 \mathrm{~h}$ at $+4^{\circ} \mathrm{C}$. Then, following lobostomy from circumference to the hilus, the anterior part of the superior pulmonary lobe and whole thyroid glands were processed for embedding in paraffin blocks by routine protocol and then sectioned by a Leica 2025 rotating microtome.

Applied routine histological staining methods. The obtained $5 \mu \mathrm{m}$ sections were stained with haematoxylin and eosin $(\mathrm{H}+\mathrm{E})$ for general histological evaluation and by Grimelius' method, revealing neuroendocrine cells, following the impregnation of their cytoplasmatic granules with silver salts [25].

Immunohistochemical reaction procedure. An immunohistochemical reaction to localize the calcitonin was performed on paraffin wax embedded sections from the thyroid and the anterior part of superior pulmonary lobe of the right lungs. Briefly, after deparaffinization and rehydratation of sections, endogenous peroxidase activity was blocked by incubation for 10 minutes in Peroxidase Blocking Reagent (Cat. no. S 2001 Dako Polska). After washing with distilled water and $0.05 \mathrm{M}$ TRIS buffer $(\mathrm{pH}=7.4)$ for 5-10 min, the sections were incubated with mouse monoclonal antibody against calcitonin (Cat. no. M 3509, Dako Polska) at a 1:50 dilution, for $30 \mathrm{~min}$, in a dark-room, at room temperature. Then, the sections were washed three times in TRIS buffer. Sections were then incubated with biotinylated secondary antibody (DAKO detection KIT LSAB (+) K 0690), prepared according to manufacturers' instructions, for $30 \mathrm{~min}$. They were then washed three times in TRIS-HCI and incubated in streptavidin solution (DAKO detection KIT LSAB (+), prepared according to manufactures' instructions for $30 \mathrm{~min}$. Then sections were incubated with DAB Liquid K 3466 (DAKO Polska), according to manufactures' instructions, for 3 minutes. For negative controls the incubation with the primary antibody was omitted and this completely abolished labeling. Human thyroid C-cells provided positive controls. Vector QS haematoxylin was used for cellular nuclei stained (only 1-2 sec.). Stained slides were then dehydrated through a series of graded ethanol, cleared in xylene and mounted in Permount (Fischer Scientific).

Quantitative analysis. The analysis of the preparations and their photographic documentation were performed using Olympus Bx50 bright-field microscope, with CCD video camera and Pentium 120 PC computer with Lucia G (Nikon, Japan) software for microscope image analysis.

CT-immunopositive cells were counted in the ten widest crosssections of the left and right thyroid lobes and in ten randomly selected microscopic fields of the analyzed lung section area, in standard fields of $0.785 \mathrm{~mm}^{2}$, using a $\times 20$ objective lens and $\times 10$ eyepiece. Three sections from each rat were analyzed. The numbers of positively labeled cells were presented as mean values per $1 \mathrm{~mm}^{2}$ of the analyzed thyroid and lung section area.

Determination of urea and creatinine levels in blood serum. Blood was collected from the heart for coagulation. Collected blood samples were left for twenty (20) minutes in room temperature to coagulate. Then, the cylinders with coagulated blood were centrifuged at 3000 RPM for fifteen (15) minutes. In obtained blood serum, urea and creatinine levels were measured in a Backman-CX4 Analyser, using an "Urée cinetique UV 800" of BioMérieux.

Determination of total calcium levels in blood serum. Concentration of calcium was measured in de-proteined blood serum by atomic spectrometry, with air-acetylene flame atomization with Zeeman background correction on Hitachi Z-5000. Control of the method's accuracy vas carried out on certified reference material human serum, "Seronorm MIO 181" (Sero AS, Norway). 
Table 1. Serum concentrations of creatinine $(\mathrm{mg} / \mathrm{dl})$, urea $(\mathrm{mg} / \mathrm{dl})$, total calcium $(\mathrm{mmol} / \mathrm{L})$ and calcitonin $(\mathrm{pg} / \mathrm{ml})$ in control group and uremic rats.

\begin{tabular}{|c|c|c|c|c|c|}
\hline & Creatynine & Urea & Tolal calcium & Calcilonin & ${ }^{*}$ p-valuc \\
\hline control & $0.52 \pm 0.052$ & $35.33 \pm 5.98$ & $2.31 \pm 0.18$ & $6.79 \pm 0.45$ & - \\
\hline 1 week & $0.63 \pm 0.092$ & $52.91 \pm 16.39$ & $2.0 \pm 0.11$ & $5.43 \pm 0.56$ & $<0.05$ \\
\hline
\end{tabular}

Determination of calcitonin levels in blood serum. Blood was collected from the heart for coagulation. Collected blood samples were left for twenty minutes in room temperature to coagulate. Then, the cylinders with coagulated blood were centrifuged at 3000 RPM for fifteen minutes. In obtained blood serum, calcitonin levels were measured in a Minigamma 1275 (Wallac) Analyzer, using calcitonin (Rat) RIA kit (Phoenix Pharmaceuticals Inc).

Ethical issues. Study assumptions, aim, schedule and mode of animal treatment were approved by the Senate Committee for Supervision of Experiments on Humans and Animals, Medical University of Białystok.

Statistical analysis. Statistical analysis was based on the variance analysis test. Verification of variance analysis assumptions was performed by Shapiro-Wilk's test (normal distribution assumption) and U-Mann-Whitney and t-Student test. The analysis was performed using the SAS ATAT software package.

\section{Results}

No significant differences were found between the control groups of rats, regarding the results of performed studies, therefore, for that reason, only the results of studies on sham-operated animals were taken into account.

Increased concentrations of urea and creatinine are one of the indicators of renal insufficiency degree.

Serum concentrations of creatinine $(\mathrm{mg} / \mathrm{dl})$, urea $(\mathrm{mg} / \mathrm{dl})$, total calcium $(\mathrm{mmol} / \mathrm{L})$ and calcitonin $(\mathrm{pg} / \mathrm{ml})$ in control group and uremic rats (Table 1).

A statistical increase of serum creatinine and urea concentrations was demonstrated in group of animals with experimental renal insufficiency, when compared with respective values in the control group (Table 1).

The induction of uremia caused decrease in total calcium concentrations and reduction of calcitonin level in uremic rats, in comparison to controls (Table 1).

Routine histopathological examination $(\mathrm{H}+\mathrm{E})$ showed normal histological structure of thyroid glands and lungs. No significant differences were seen between the control rats and the experimental animals.

The thyroid glands and lungs showed cells with a characteristic positive argyrophilic - cells which typically belong to the DNES. The number of cells, revealed by Grimelius' method was lower in the thyroid glands and positively higher in the lungs of uremic rats, than in the animals of the control group (Fig. $1 \mathrm{~A}$ and $\mathrm{B})$.
After immunohistochemical labeling of calcitonin (seen as darkly stained cytoplasmic granules), the location and shape of CT-positive cells was clearly demonstrated.

In the thyroids of the rats used in the experiment, $\mathrm{C}$ cells were generally single and occurred most frequently in central areas of the glands. In the areas of their particular concentration, $\mathrm{C}$ cells formed small groups. Single cells were long in shape, fusiform, sometimes rounded or multilateral (if in a group). A strong CT-positive reaction was observed in the cytoplasm of C cells, which allowed for easy identification of probably all cells in the sections that underwent morphometrical analysis. Computer analysis of CTpositive cells demonstrated a statistically significant decrease in the number of $\mathrm{C}$ cells in thyroids of rats one week after nephrectomy $(175.21 \pm 0.26 ; \mathrm{p}<0.001)$ when compared to the values in the control animals $(221.95 \pm 0.43)$ (Fig. 2A and B).

The immunohistochemical studies revealed a positive cytoplasmatic reaction in neuroendocrine cells of lung in all the rats examined. The CT-positive cells were clearly distinguishable in structures of the lungs and they were surrounded by other cells of the respiratory tract epithelium, were distinctive by shape variety, from pyramidal to polygonal, oval or even columnar.

In the lungs of the examined rats NE cells occurred in the respiratory tract scattered single or in groups. Single NE cells, as well as NEB were localized at various levels of the respiratory tract of studied rats. After one week of uremia, a distinct increase in the number of CT-immunopositive cells was observed. Single NE cells, as well as NEBs, were localized at various levels of the respiratory tract of studied rats. Both in inferior bronchia and bronchioli, there were numerous but small (2-5 cells) clusters of PNEC. NEB, with higher numbers of neuroendocrine cells were only sometimes identified.

Computer analysis of CT- immunoreactive PNE cells demonstrated a statistically significant increase in the number of CT-positive cells in the lungs of rats with experimentally induced renal insufficiency $(3.52 \pm 0.46$; $\mathrm{p}<0.001$ ), when compared to the value in the control animals $(1.58 \pm 0.17 ; \mathrm{p}<0.001)$ (Fig. $3 \mathrm{~A}$ and $\mathrm{B}$ ). 

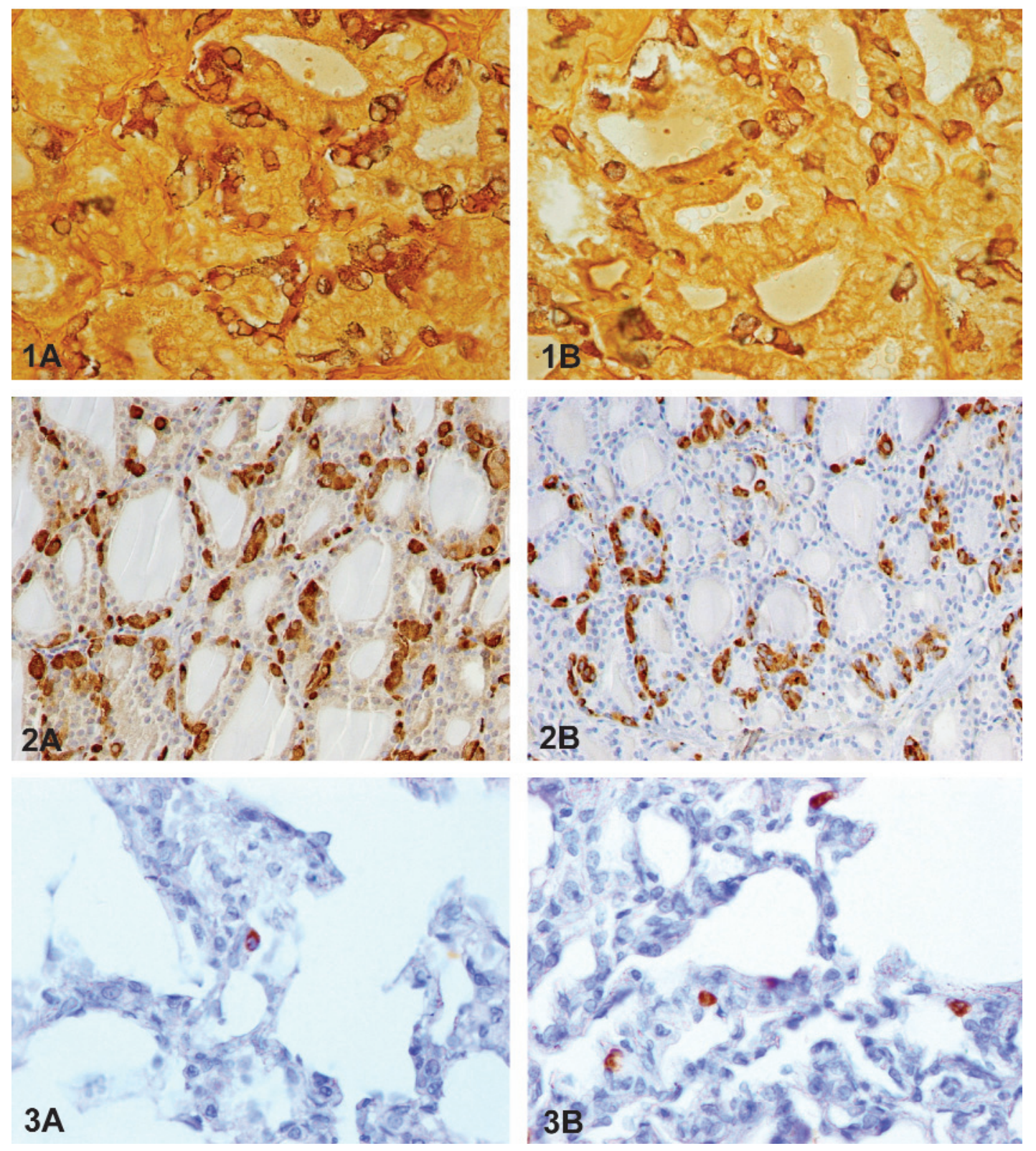

Fig. 1. The thyroid gland of $(\mathbf{A})$ control rat and $(\mathbf{B})$ uremic rat. Grimelius met. (original magnification $\times 200)$. Fig. 2. The thyroid gland of (A) control rat and (B) uremic rat. Strong CT- immunolabelling in the cytoplasm of C cells (dark-colored granules) (original magnification $\times 200)$. Fig. 3. Rat lung (A) of control rat (single NE cell), (B) uremic rat. NE cells show distinctly CT - immunopositive reaction (original magnification $\times 200$ ).

\section{Discussion}

One of the best renal insufficiency indicators is serum creatinine and urea concentration. The significant increase in serum urea and creatinine concentration, obtained during the performed experiment in blood serum of the uremic rats, comparing to that in the control animals, confirmed the experimentally induced renal insufficiency.

The kidneys are the major site where peptide hormones are biodegraded, inactivated and excreted $[22,26,27]$. Hormonal disorders are the permanent symptoms of renal failure. They concern all known hormones and can be due to quantitative changes of the secretory activity and disturbances of endocrine cells functions. Damage to a considerable percentage of nephrons leads to excretory and endocrine dysfunction of the kidneys, and to serious changes in metabolic processes. These disturbances together with compensatory processes that occur in the kidneys and in other organs during CRF have definite clinical and biological consequences. It is still not known what particular factor is directly responsible for various organ changes in uremia. The clinical symptoms observed in renal failure may, to a certain degree be connected with 
of calcitonin-producing cells activity disorders, because of their high sensitivity to environmental changes and the extremely broad activity spectrum inducing different biological effects $[21,28]$.

The hormone secretion of most endocrine organs is regulated by a negative feedback system by which synthesis, secretion of hormone and cell growth are controlled.

In the present study, short-term of uremia was examined and showed decreased in the number of the thyroid $\mathrm{C}$ cells and reduction of $\mathrm{CT}$, and total calcium in the serum of rats. Whether CRF induced negative feedback to the activity of $\mathrm{C}$ cells directly through calcitonin receptor on $\mathrm{C}$ cells or indirectly via calcium or the other factors was not answered by these results. Thyroid hormones may affect renal function in many ways; and in contrast, renal functional disturbances may affect thyroid function.

The decrease in the total number of C-producing cells after one week the uremia-inducing surgery may have been associated with either impaired synthesis or a heightened demand for the hormone resulting from the disorders of the internal environment caused by renal insufficiency. It is rather difficult to explain the behavior of the thyroid parafollicular cells in renal failure because, in the studies to date, very little attention has been devoted to the evaluation of DNES cells in the body in the course of renal insufficiency. However, there are many reports suggesting that renal disorders leading to disturbances in the biosynthesis of biologically active substances, cause changes in the thyroid activity $[20,21,28,29]$ but there are no date on the pathogenesis of altered $\mathrm{C}$ cells in CRF.

In $\mathrm{CRF}$ conditions, lung CT-producing cells reacted differently compared to thyroid $\mathrm{C}$ cells. In the performed experiment, similarly as in the preliminary studies [19,30], a distinct increase in the general number of neuroendocrine cells producing calcitonin was observed in different respiratory tract sections of uremic rats, comparing to the control animals. It was found in a subjective evaluation of cells, stained with silver salts and in the applied immunohistochemical reaction, and confirmed in morphometric studies of neuroendocrine cells with CT expression. Quantitative analysis demonstrated a statistically significant increase in the number of studied cells in group of rats with experimentally induced uremia $(p<0.001)$, when compared with the control animals. Taking into account the general evaluation and statistic analysis of the results, it appears that CT secretion and function in lung neuroendocrine cells involves different, perhaps local, regulatory mechanisms than those of thyroid $\mathrm{C}$ cells.

In this experiment, the increased number of $\mathrm{CT}-$ producing cells, observed in the group of uremic rats, could be either absolute, i.a., caused by proliferation of those cells, or relative, i.a., resulting from an enhanced synthesis of amines and peptide hormones or from impaired mechanisms of their release. It is to be assumed that those changes were induced by disorders in hormonal and electrolyte metabolism.

Taking into consideration homeostatic disturbances of the organism induced by the impairment of renal parenchyma and a key role of neuroendocrine cells in many organs which regulate the functioning of the organism it should be assumed that CT-producing cells are greatly involved in the chain of physiological events taking place in the thyroid glands and lungs in uremia. However, as long as the mechanisms of mutual relations and interactions are not elucidated, it is difficult to determine whether the principal abnormality of thyroid function and clinical symptoms from the respiratory system observed in patients with CRF result from the impairment of structure and function of single DNES cells, or are due to the reaction of enteroendocrine cells to homeostatic disorders. This can be explained by the fact that the products synthesized in DNES cells, also act as tissue hormones which indirectly control and regulate homeostasis.

It can be concluded that CRF leads to disorders of the CT-production cells in the thyroid gland and lungs. These disorders include quantitative changes, leading to disturbances in the release of calcitonin. It may be assumed that morphological and functional changes of CT-production cells of the thyroid and lungs are a compensatory phenomenon for the adjustment of disorders of hormonal and electrolyte balances induced by CRF. Elucidation of the mechanisms that affect the morphology and activity of DNES cells, as well as a complete understanding of the changes may be significant for diagnostic purposes.

\section{References}

[ 1] Gould VE, Linnoila RI, Memoli VA and Warren WH. Neuroendocrine components of the bronchopulmonary tract: hyperplasias, dysplasias and neoplasms. Lab Invest. 1983;49:519-537.

[ 2] Ito T. Differentiation and proliferation of pulmonary neuroendocrine cells. Prog Histochem Cytochem. 1999;34:247-322.

[ 3] Kasacka I, Sawicki B and Ostrowska H. Pulmonary neuroendocrine cells in chronic renal failure. Rocz Akad Med Bialymst. 2004;49:149-151.

[4] Keith I and Will JA. Dynamics of the neuroendocrine cell regulatory peptide system in the lung. Specific overview and new results. Exp Lung Res. 1982;3:387-402.

[5] Kvetnoy I, Popuichiev V, Mikhina L et al. Gut neuroendocrine cells: relationship to the proliferative activity and apoptosis of mucous epitheliocytes in aging. Neuroendocrinol Lett. 2001;22:337-341.

[ 6] Oster A, Jensen J, Edlund H and Larsson LI. Homeobox gene product Nkx 6.1 immunoreactivity in nuclei of endocrine cells of rat and mouse stomach. J Histochem Cytochem. 1998;46:717-721.

[7] Buvry A, Yang Y-R, Tavakoli R, and Frossard N. Calcitonin gene-related peptide - immunoreactive nerves and neuroen- 
docrine cells after lung transplantation in the rat. Am J Respir Cell Mol Biol. 1999;20:1268-1273.

[8] Marchevsky AM and Kleinerman J. Immunocytochemical studies of APUD cells in airways: effects of nitrosodiethylamine and nitrogen dioxide. Arch Pathol Lab Med. 1982; 106:400-403.

[ 9] Rydzewska-Rosolowska AE, Kasacka I, Sulewska A, Rudy A and Chyczewski L. Pulmonary neuroendocrine cells in physiology and pathology. Folia Histochem Cytobiol. 2001;39:58-63.

[10] Kasprzak A, Seidel J and Zabel M. Demonstration of calcitonin mRNA in rat thyroid C-cells and endocrine cells of the lung: comparison of immunocytochemical and hybridocytochemical results. Folia Histochem Cytobiol. 1996;34:9-10.

[11] Sawicki B, Kasacka I, Azzadin A et al. Preliminary evaluation of endocrine cells in the rat respiratory tract after thyroid and parathyroid gland removal. Folia Histochem Cytobiol, 2001; 39:193-194.

[12] Harbarth S, Holeckova K, Froidevaux C et al. Diagnostic value of procalcitonin, interleukin- 6 , and interleukin- 8 in critically ill patients admitted with suspected sepsis. Am J Respir Crit Care Med. 2001;164:396-402.

[13] Montuenga LM, Guembe L, Burrell MA et al. The diffuse endocrine system: from embryogenesis to carcinogenesis. Prog Histochem Cytochem. 2003;38:155-272.

[14] Calvo R, Morreale de Escobar G, Escobar del Rey F and Obregon MJ. Maternal nonthyroidal illness and fetal thyroid hormone status, as studied in the streptozotocin-induced diabetes mellitus rat model. Endocrinology. 1997;138:11591169.

[15] Davis FB, Spector DA, Davis PJ, Hirsch BR, Walshe JJ and Yoshida K. Comparison of pituitary-thyroid function in patients with endstage renal disease and in age- and sexmatched controls. Kidney Int. 1982;21:362-364.

[16] Kalender B, Erk M, Pekpak M et al. The effect of renal transplantation on pulmonary function. Nephron. 2002;90:72-77.

[17] Numano M, Tominaga Y, Uchida K, Orihara A, Tanaka Y and Takagi H. Surgical significance of supernumerary parathyroid glands in renal hyperparathyroidism. World J Surg. 1998;22: 1098-1102.
[18] Słomian M, Mosiewicz J and Myśliński W. Lung function in chronic uremia. Ann Univ Mariae Curie Sklodowska LublinPolonia Sectio D. LV. 2000;23:147-153.

[19] Kasacka I, Azzadin A, Sawicki B and Malla H. Immunoreactivity of neuroendocrine cells in the respiratory tract in rats with experimental uremia after thyroparathyroidectomy. Folia Histochem Cytobiol. 2001;39:64-65.

[20] Łebkowska U, Malyszko J, Łebkowski WJ, Walecki J and Mysliwiec M. Is there any relation between thyroid gland function and kidney transplant function? Transplant Proc. 2003;35:2222-2223.

[21] Kaptein EM. Thyroid hormone metabolism and thyroid diseases in chronic renal failure. Endocr Rev. 1996;17:45-63.

[22] Więcek A and Kokot F. Endocrine disorders in patients with chronic renal failure. Postepy Hig Med Dośw. 1989;43:423-451.

[23] Giles AR. Guidelines for the use of animals in biomedical research. Thromb Haemost. 1987;58:1078-1084.

[24] Ormord D and Miller T. Experimental uremia. Nephron. 1980;26:249-254.

[25] Grimelius L. A silver nitrate stain for 2 cells in human pancreatinic islets. Acta Soc Med Uppsa. 1968;73:243-294.

[26] Sirinek KR, O'Dorisio TM, Gaskill HV and Levine BA. Chronic renal failure: effect of hemodialysis on gastrointestinal hormones. Am J Surg. 1984;148:732-735.

[27] Patel VA, Logan A, Watkinson JC et al. Isolation and characterization of human thyroid endothelial cells. Am J Physiol Endocrinol Metab. 2003;284:168-176.

[28] Reinhardt W, Misch C, Jockenhovel F et al. Triiodothyronine (T3) reflects renal graft function after renal transplantation. Clin Endocrinol (Oxf). 1997;46:563-569.

[29] Lim VS, Henriquez C, Seo H, Refetoff S and Martino E. Thyroid function in a uremic rat model. Evidence suggesting tissue hypothyroidism. J Clin Invest. 1980;66:946-954.

[30] Azzadin A, Kasacka I, Sawicki B, Malla H, Dadan J and Buczko W. Preliminary evaluation of neuroendocrine cells in the respiratory tract in rats with experimental uremia. Folia Histochem Cytobiol. 2001;39:205-206.

Submitted: 27 November, 2007 Accepted after reviews: 25 April, 2008 